\title{
Evaluation of the Level of Safety and Disaster Preparedness of Comprehensive Healthcare Centers in Babol, Iran
}

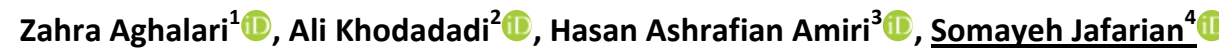

Date of submission: 21 Dec. 2018 Date of acceptance: 29 Dec. 2019

\begin{abstract}
INTRODUCTION: Comprehensive healthcare centers should be able to provide primary healthcare services during disasters; therefore, it is necessary to assess their safety and preparedness to ensure that they can have acceptable functionality in critical situations. In this regard, the present study aimed to evaluate the level of safety and disaster preparedness of comprehensive healthcare centers in Babol, Iran.

METHODS: The present descriptive cross-sectional study was conducted in 2016 to investigate the safety level and disaster preparedness of 232 comprehensive healthcare centers in Babol, using observation and checklists. The used checklist consisted of three parts, namely functional, structural, and non-structural safety assessment. Finally, the collected data were analyzed using descriptive statistics.

FINDINGS: Based on the data analysis, the studied centers were more prone to weather hazards than other types of disasters. Moreover, the evaluation of the different aspects of the functionality of the centers showed that the best functionality was observed in firefighting, provision of the environmental health services, organization and structure, and provision of infectious disease management services, in that order. The non-structural safety obtained the highest average score (37.49) while the scores of functional and structural safety were 21.76 and 9.27, respectively.

CONCLUSION: Based on the results, all the studied comprehensive healthcare centers had a moderate level of structure and functional safety, while no center had a completely desirable level. Therefore, it is recommended to develop proper plans and monitor the comprehensive healthcare centers to eliminate their defects and improve the level of their safety.
\end{abstract}

Original Article

Keywords: Comprehensive Healthcare Centers; Disasters; Preparedness; Safety.

How to cite this article: Aghalari Z, Khodadadi A, Ashrafian Amiri H, Jafarian S. Evaluation of the Level of Safety and Disaster Preparedness of Comprehensive Healthcare Centers in Babol, Iran. Sci J Rescue Relief 2019; 11(4): 287-93.

\section{Introduction}

$\mathrm{D}$ isasters have many adverse economic, social, psychological, and cultural consequences (1). Iran is one of the most disaster-prone countries, especially natural disasters (2) since approximately 31 out of the 40 known natural disasters have occurred in this country. In general, Iran is one of the 10 most disaster-prone countries in the world and $90 \%$ of its population is exposed to earthquakes and floods (3-4). Iran ranks fourth in Asia (after India, China, and Bangladesh) and sixth in the world among the victims of natural disasters (5). According to the Global Assessment Report on

1-M.Sc, Environmental Health Engineering, School of Public Health, Babol University of Medical Sciences, Babol, Iran

2-Expert in Charge of Babol Disaster Unit, Health Department, Babol University of Medical Sciences, Babol, Iran

3-Health Deputy, Head of the Healthcare Center, Health Department, Babol University of Medical Sciences, Iran

3-M.Sc, Health Services Management, B.A. in Environmental Health Engineering, Health Department, Babol University of Medical

Sciences, Babol, Iran

Correspondence to: Somayeh Jafarian, Email: jafarian.s51@gmail.com 
Disaster Risk Reduction released in 2009, the disaster risk level of Iran was estimated at 8 out of 10 (6).

Iran accounts for only $1 \%$ of the world's population; however, it accounts for more than $6 \%$ of disaster losses in the world. Therefore, there is obviously a need to pay attention to disaster management in this country (7). Among the various components of disaster management, comprehensive healthcare centers and hospitals definitely play the most significant role due to their responsibility regarding the maintenance of the healthcare of the community (8).

In other words, comprehensive healthcare centers are considered the symbol of health. They should be able to deliver appropriate healthcare services, guarantee the safety of their patients, clients, and staff, and provide the required equipment in critical situations as they do in normal situations (9).

If comprehensive healthcare centers become damaged during a disaster for any reason, they lose the ability to provide appropriate healthcare services which leads to a kind of secondary crisis. Therefore, it is essential to make sure of the structural and functional safety of comprehensive healthcare centers in critical situations (5).

Negligence of the level of safety and disaster preparedness of comprehensive healthcare centers will cause irreparable damage to the country's economy. For instance, in the United States, the damage caused by disasters to the health infrastructure in 15 years was estimated at 3 billion dollars. There are various statistics on the damages of natural disasters to healthcare centers around the world, including the Gujarat earthquake in India with the destruction of 3812 healthcare centers and the complete disruption of the regional healthcare system, the floods in Indonesia in 2006 with the complete destruction of one hospital and overcrowding in other hospitals and the earthquake in Pakistan in 2005 that destroyed 400 healthcare centers and 13 hospitals (10).

In Iran, a noticeable example is the Bam earthquake in 2003, in which all healthcare centers and hospitals were completely destroyed followed by physical, bodily, and long-term economic harms (11-12). When natural or human-made disasters, the basic task of healthcare centers is to provide emergency services for the victims.

Therefore, healthcare centers should always be prepared for disasters. Moreover, in order to reduce the harmful effects and consequences of accidents and disasters, they should develop a comprehensive crisis management plan by making appropriate physical, industrial, structural, and managerial arrangements (13-14). Therefore, it is necessary to assess the level of safety and disaster preparedness of healthcare centers. In this regard, the present study aimed to evaluate the level of safety and disaster preparedness of comprehensive healthcare centers in Babol, Iran.

\section{Methods}

The present cross-sectional descriptive study aimed to evaluate the comprehensive healthcare centers in Babol regarding their level of safety status and disaster preparedness. This evaluation was performed as part of the safety and risk assessment (SARA) program in 2016. The level of safety of comprehensive healthcare centers was assessed using a valid checklist provided by the Ministry of Health for all health departments of medical universities. The used checklist was prepared by the Risk and Disaster Management Unit of the Ministry of Health (15).

The checklist was scored in each of the comprehensive healthcare centers by disaster experts who had passed the necessary training courses based on the direct observation of the function of the crisis management structure and evaluation of functional, structural, and nonstructural factors.

This checklist had five sections, which included 1) the information of the health department and the comprehensive healthcare centers in its catchment area, 2) recognition of the geological, climatic, social, environmental, technological, and manmade hazards, 3) assessment of the functional safety, such as the formation of a crisis committee, development of an operational plan for internal and external hazards as well as the maintenance and reconstruction of critical services, and access to emergency medicine, equipment, and supplies, 4) assessment of the non-structural safety, including critical systems, electrical systems, communication systems, water storage systems, fuel storage, heating and air conditioning systems, office equipment (fixed and mobile), and medical and laboratory equipment, 5) assessment of the structural safety, such as the previous incidents that affected the safety of the department, the safety of the structural system, and the type of 
materials used in the building.

The types of disasters were scored based on the four levels of 0 (lack of disasters), 1-50 (mild disasters), 51-75 (moderate disasters), 76-100 (severe disasters). Moreover, the non-structural, functional, and structural factors were scored based on the three levels of 0 (undesirable), 1-50 (moderate), and 51-100 (desirable). Furthermore, the level of safety was scored according to the four levels of 0 (not safe), 1-5 (low-level safety), 5-7 (moderate-level safety), and 6-10 (high-level safety). The collected data were analyzed using descriptive statistics.

\section{Findings}

Babol is located in the north of Iran and has a population of about 524,069 people. This city is adjacent to Ghaemshahr in the east, Amol in the west, Babolsar in the north, and Alborz mountain range in the south. The catchment area of the health department of Babol includes 34 comprehensive urban and rural healthcare centers and 177 local health centers (Table 1).

The disasters that have occurred in the city of

Table 1. Comprehensive healthcare centers in the catchment area of Babol University of Medical Sciences based on type and number-2016

$\begin{array}{cc}\text { Type of the Center } & \text { Number } \\ \text { Urban comprehensive healthcare centers } & 9 \\ \text { Rural comprehensive healthcare centers } & 25 \\ \text { Urban attached healthcare unit } & 9 \\ \text { Non-urban attached healthcare unit } & 12 \\ \text { Urban-rural healthcare unit } & - \\ \text { Local healthcare center } & 177 \\ \text { Healthcare headquarters of the city } & 1 \\ \text { Total number of healthcare centers } & 232\end{array}$

Babol during the past years include flood, torrential rains, storm, earthquake, landslides, heavy snow, and gas, electricity, and water cuts. Moreover, the risk of danger is currently more than before due to climate change. The known disasters in the comprehensive healthcare centers were divided into 5 sections and most of them were related to weather hazards, while none of the risks were at a high level (Table 2).

In Figure 1, the significance of the disasters is scored based on a scale from 0 to 100; accordingly, 0 indicates the lack of disasters while 100 indicates the occurrence of the most severe disasters. There were only two cases of moderate disasters, which included hurricanes and torrential rains; in fact, weather hazards were the most common disasters (Figure 1).

According to the evaluation of the different aspects of the functionality of centers, the best functionality was observed in firefighting, provision of the environmental health services, organization and structure, and provision of infectious disease management services, in that order. On the other hand, the most insignificant functionality in the centers was observed in the finance, water and food storage, and personal equipment storage. (Figure 2)

Table 2. Risk of different types of hazards in the comprehensive healthcare centers of Babol-2016

\begin{tabular}{lc} 
Disasters & Risk (out of 100) \\
\hline Weather & 14.61 \\
Geological & 12.56 \\
Environmental & 10.44 \\
Technological and human-made & 6.78 \\
Social phenomena & 2.32 \\
Total disasters & 9.34 \\
\hline
\end{tabular}

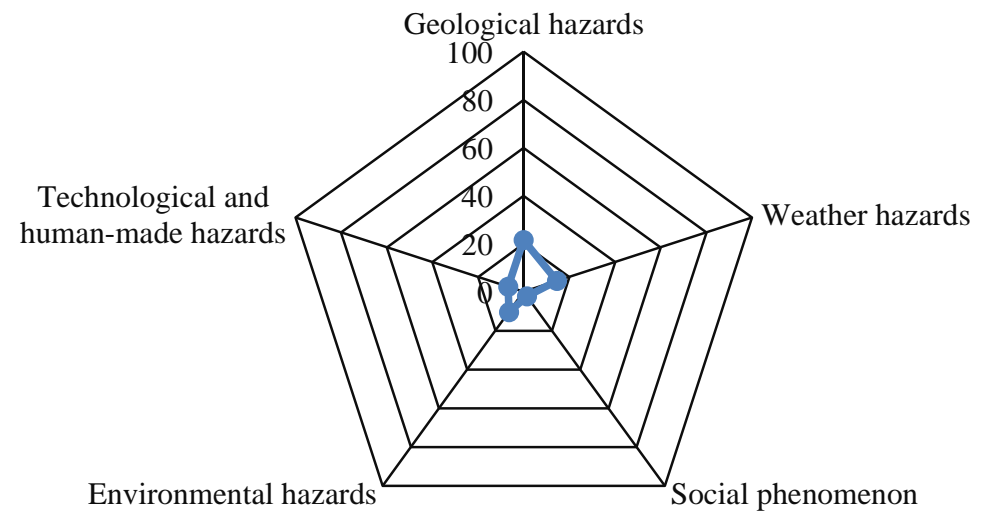

Figure 1. Risk of different types of hazards in the comprehensive healthcare centers of Babol-2016 
Organization and structure Preparation plan

Risk evaluation

Risk reduction measures Insurance coverage

Coordination

Response management system Communication and early warnings

Evacuation

Damage and requirement evaluation

Technical supplies and equipment storage Equipment and personal safety tools storage

Food and water storage

Mental health of the staff and their families

Continuous provision of services

Transportation

Management of the received help and volunteers

Finance

Information safety

Water, electricity, and gas safety

Management of important visitors

Security

Awareness raising

Rapid response team

Firefighting

Marketing

Practice

Education

Provision of the environmental health services

Provision of infectious disease management services

Provision of non-infectious disease management.

Provision of pregnancy health services

Provision of food services

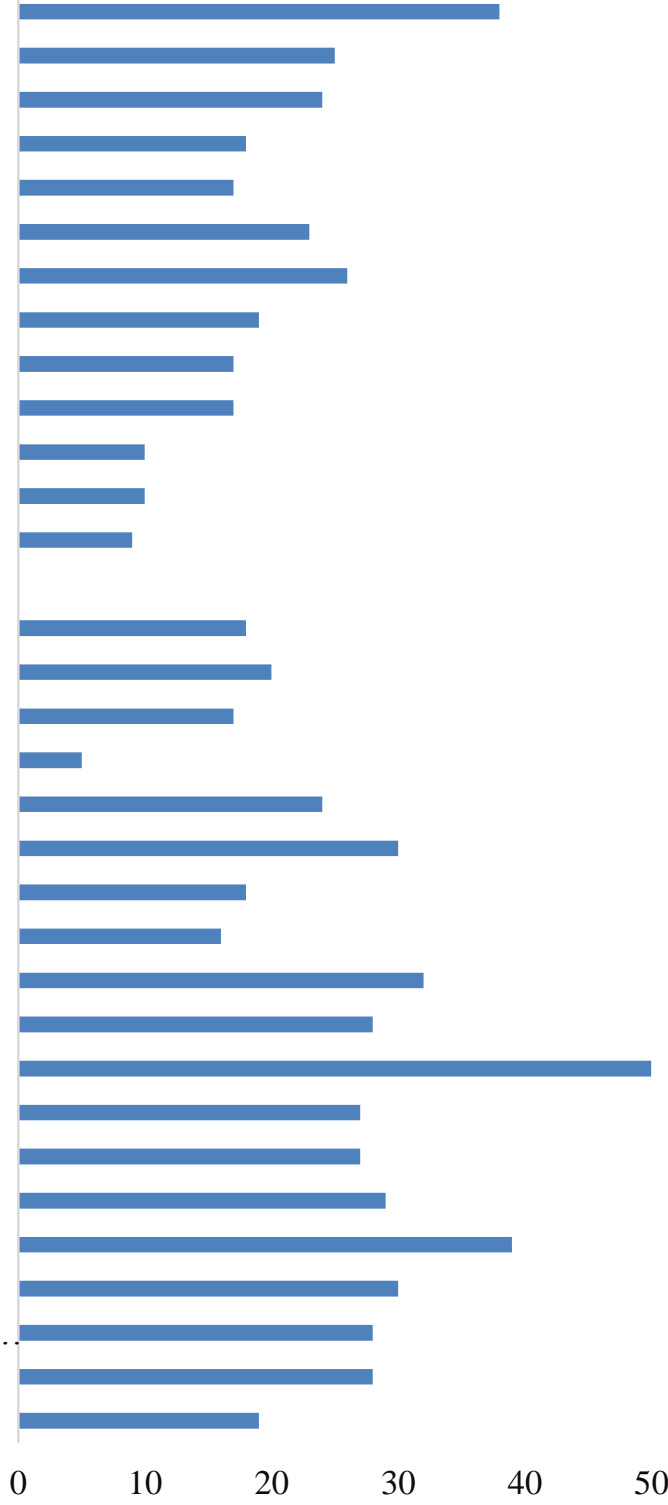

60

Figure 2. Disaster preparedness of the studied comprehensive healthcare centers-2016

For the purposes of the study, first, the scores of the three categories of functional, nonstructural, and structural safety were calculated for each of the studied comprehensive healthcare centers and then the overall mean score of the mentioned sections was obtained. The mean scores of all the four studied categories were moderate according to the above-mentioned levels and none of them were undesirable and desirable. Moreover, the non-structural factors obtained the highest mean score. (Table 3)

In line with the implementation of the SARA, the comprehensive healthcare centers were evaluated regarding the extent of their adherence to the program of the reduction of their structural and non-structural vulnerability. Based on the results, the levels of adherence to the abovementioned plan in the local healthcare centers and urban/rural comprehensive healthcare

Table 3. Mean scores of comprehensive healthcare centers in Babol regarding the functional, structural, and non-structural safety-2016

\begin{tabular}{lc} 
Levels & Mean scores (out of 100) \\
\hline Non-structural factors & 37.49 \\
Functional factors & 21.76 \\
Structural factors & 9.27 \\
Level of safety & 3 out of 10 \\
\hline
\end{tabular}




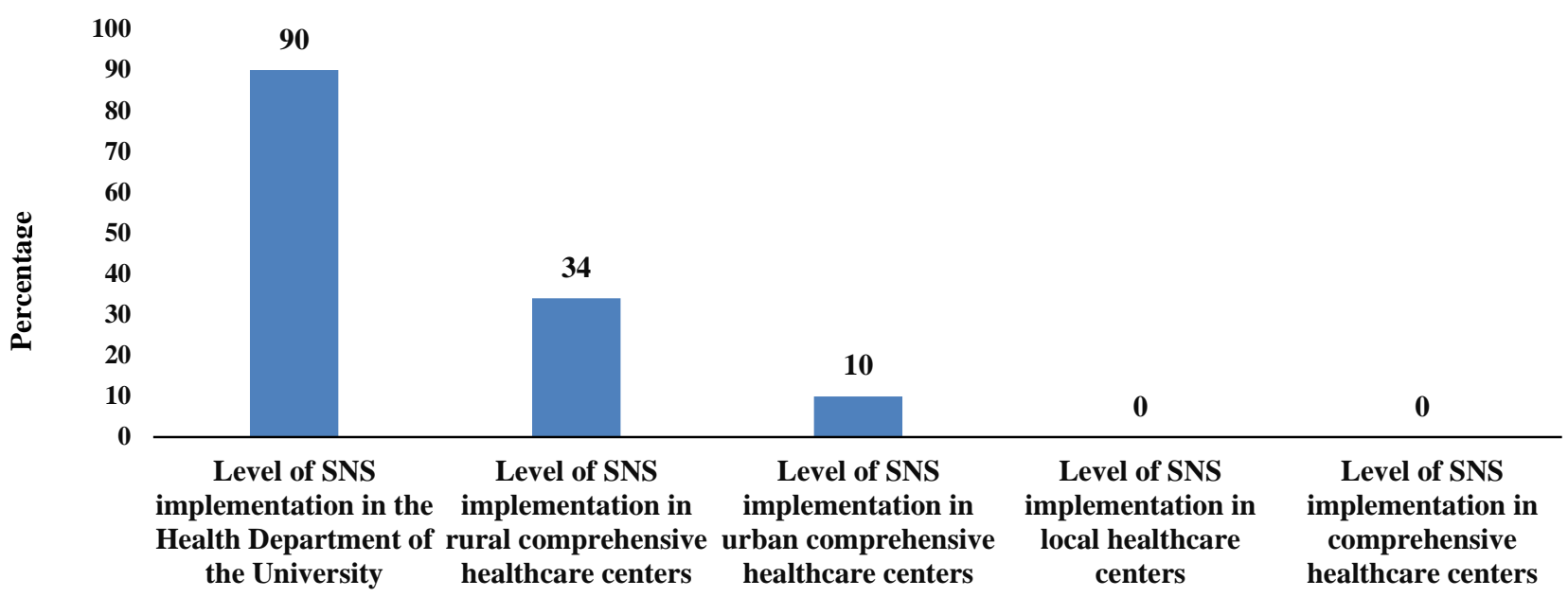

Figure 3. Program of reduction of structural and non-structural vulnerability in comprehensive healthcare centers in Babol-2016

centers of Babol were 0 and up to $34 \%$, respectively. (Figure 3)

\section{Discussion and Conclusion}

Based on the results, evaluation of the different aspects of the functionality of the centers indicated that the best functionality was observed in firefighting, provision of the environmental health services, organization and structure, and provision of infectious disease management services, in that order. The highest mean score was 37.49 and belonged to the non-structural factors that were at the moderate level. Similarly, based on the findings of a study conducted by Tabrizi et al., the score of non-structural factors in the comprehensive healthcare centers of Tabriz was 37.43 (16).

According to the results of a study performed by Torkzadeh et al., which evaluated the safety of comprehensive urban and rural healthcare centers, local healthcare centers, and healthcare centers in Isfahan against disasters, the mean scores of nonstructural factors in urban and rural centers were 74.2 and 82.5 , respectively (17).

Given that the mean value of the scores of nonstructural factors in the present study was low, a correct and comprehensive evaluation before the disasters will help to estimate the real efficiency of medical centers in times of crisis, take preventive measures, and increase disaster preparedness. Therefore, plan development and organization of the equipment, human resources, and other required resources will be more purposeful and accurate.

The mean value of the level of safety of the studied centers was 3 out of 10 which is low and undesirable. Najafi et al. in their study found that the level of preparedness of comprehensive healthcare centers of Bam before, during, and after the disaster was 5 out of 10 which is undesirable (18).

Based on the findings of a study conducted by Kooti et al., the level of preparedness of Health Centers in Ahwaz before, during, and after the disaster was 4 out of 10 which is also undesirable (19). The results of these studies are in line with those of the present study and indicate the need for the development of a careful plan to improve the level of safety of healthcare centers.

In the present study, the functionality of the centers was poor, while the meetings of the crisis committee and the presence of environmental health and infectious disease experts were at a moderate level. In a study conducted by Mirzaei et al., there was no crisis committee in the studied hospitals, no plan was developed regarding internal and external disasters, there were no maneuvers, and the staff was not trained (20).

However, the regular meeting of the crisis committee followed by training can increase the understanding of the staff of comprehensive healthcare centers and hospitals regarding the proper behavior in critical situations, which can reduce or prevent irreparable bodily and financial harm. In the present study, the level of safety of water, electricity, and gas, and the charge of fire 
extinguishers were moderate. Moreover, adequate and safe fire extinguishers were available in all the studied centers which were regularly monitored.

Jonidi Jafari et al. in their study performed a risk assessment of functional, non-structural, and structural aspects of comprehensive urban healthcare centers in the catchment area of Iran University of Medical Sciences and found that the highest level of safety among functional factors belonged to awareness-raising, firefighting, and structure organizing (21). Provision of adequate and safe fire extinguishers that are regularly recharged is among the essential activities for firefighting in comprehensive healthcare centers and should receive special attention.

In the present study, the finance, water and food storage, and personal equipment storage had the poorest functionality, in that order. Similarly, in the study carried out by Jonidi Jafari et al., water and food storage and personal equipment storage were not at the desired level in the comprehensive healthcare centers in the catchment area of Iran University of Medical Sciences (21). Therefore, according to the abovementioned findings, it can be said that more attention should be paid to various aspects of functional safety, especially water, food, and personal equipment storage in healthcare centers.

Furthermore, it was found that all the studied centers were in good condition in terms of heating, cooling, and ventilation systems. In a study performed by Mirzaei et al., the pipes and fittings of the cooling and heating systems of the studied hospitals were not flexible and vulnerable to earthquake damage. Moreover, in the present study, the engine rooms had a moderate level and were difficult to access (20).

Basically, heating, cooling, and ventilation systems are among the most vulnerable parts to earthquake which was also expected. Therefore, all the equipment of such systems should be properly braced; moreover, flexible joints should be used at the place of the connection of pipes and cables to the equipment to make them safe against earthquakes.

In conclusion, according to the results, the level of safety and structural and functional factors of all the comprehensive healthcare centers was moderate and no center had a completely desirable level. Therefore, a proper and comprehensive assessment before the occurrence of disasters makes it possible to estimate the real efficiency of comprehensive healthcare centers in times of crisis, take preventive measures, and increase their preparedness for disasters. It is also necessary to develop appropriate plans and organize the equipment, human resources, and other required resources more purposefully and carefully.

It is also suggested to develop appropriate plans and monitor the healthcare centers periodically to improve their deficiencies and enhance their level of safety. Moreover, the managers of such centers should be trained in disaster management and develop necessary plans for these centers to reach the international standard level which is the completely desirable level.

\section{Acknowledgments}

The authors would like to express their gratitude to the Health Department of Babol University of Medical Sciences for its moral and material support.

\section{Conflict of Interests}

There is no conflict of interest regarding the publication of this study.

\section{References}

1. Aghalari Z, Tirgar A. Topics of disasters in scientific outputs of medical sciences: a crosssectional study. Health Emerg Disast 2017; 2(2): 47-52.

2. Ainehvand S, Raeissi P, Ravaghi H, Maleki M. Natural disasters and challenges toward achieving food security response in Iran. J Edu Health Promot 2019; 8: 51.

3. Tarrahi M, Hamouzadeh P, Bijanvand M, Lashgarara B. The quality of health care services provided in health care centers of Khorramabad using SERVQUAL model in 2010. Yafte 2012; 14(1): 13-21. [In Persian].

4. Sorani M, Tourani S, Khankeh HR, Panahi S. Prehospital emergency medical services challenges in disaster; a qualitative study. Emergency 2018; 6(1): e26.

5. Mastaneh Z, Jahangiri M, Doost M, Eshghi A, Mouseli L. Strengths and weaknesses of disaster management in hospitals of Hormozgan Medical Sciences Universities. Journal Fasa Med Sci Univ 2011; 1(4): 244-50. [In Persian].

6. Abedi G, Mousazadeh M, Ranjbar M, Abedini E. Developmental levels of educational hospitals for 
confronting the unexpected disasters in Mazandaran province. J Mazandaran Univ Med Sci 2017; 27(148): 79-87. [In Persian].

7. Jahangiri K, Tabibi SJ, Maleki MR, Alamdari SH. A comparative study on community-based disaster management (cbdm) in selected countries and proposing a model for Iran. Payesh $\mathbf{J} 2009$; 8(1): 49-57. [In Persian].

8. Amiri M, Mohammadi G, Khosravi A, Chaman R, Arabi M, Sadeghi E, et al. Hospital preparedness of Semnan province to deal with disasters. Knowl Health 2011; 6(3): 44-9. [In Persian].

9. Nejad Shafiee M, Sarhangi F, Rahmani A, Salari MM. Necessity for learning the knowledge, and skills required for nurses in disaster. Educ Strat Med Sci 2017; 9(5): 328-34. [In Persian].

10. United Nations International Strategy for Disaster Reduction (UNHCR). Global Assessment Report on Disaster Reduction. Geneva: World Water Assessment Programmed; 2009.

11. Ardalan A, Najafi A, Sabzeghabaei A, Zonobi V, Ardalan S, Khankeh HR, et al. Native model index of hospital risk assessment in disaster. J Hospital 2010; 9: 321-7. [In Persian].

12. World Health Organization (WHO). Pan American Health Organization (PAHO);(2005), "Safe hospitals, a collective responsibility, a global measure of disaster reduction". Geneva: World Health Organization; 2009.

13. Vahedparast H, Ravanipour M, Hajinezhad F, Kamali F, Gharibi T, Bagherzadeh R. Assessing hospital disaster preparedness of Bushehr province. Iran South Med J 2013; 16(1): 69-76. [In Persian].

14. Ardalan A, Rajaii MH, Masoumi G, Ahmadnejad E, Azin SA, Zounobi $\mathrm{W}$, et al. The plan of Management and reduction of disasters danger in Islamic Republic of Iran. J Health Syst Res 2011;
7(6): 202. [In Persian].

15. Ardalan A. Checklist used by ministry of health risk reduction and disaster management unit. Tehran: Razenahan; 2011. [In Persian].

16. Tabrizi J, Gharibi F, Mohammadi Z. Survey level of physical safety of health care centers in Tabriz in 2015. The 1st Annual Conference of Health Management in Disasters and Emergencies, Tabriz, Iran; 2016. [In Persian].

17. Takzadeh H, Afshari S, Sokhanvari F, Jafari M. Safety assessment of urban and rural health services centers, Isfahan health homes and health centers in barriers and emergencies 2015. 8th Asian Safe Community Summit and the first Mashhad Safe Community Regional Meeting, Mashhad, Iran; 2017. [In Persian].

18. Najafi K, Akbarian M, Rezaei M, Faramarzpour. Disaster risk assessment in functional, nonstructural \& structural components for health centers of bam university medical of science. The 1st Annual Conference of Health Management in Disasters and Emergencies, Tabriz, Iran; 2016. [In Persian].

19. Koti M, Nisi A, Hatami H, Jahanbani E. Functional, non-structural and structural readiness of Ahvaz health centers for disasters in 2014. 6th International Conference on Comprehensive Crisis Management, Mashhad, Iran; 2014. [In Persian].

20. Jafari AJ, Baba M, Dowlati M. Disaster risk assessment in health centers of Iran University of Medical Sciences in functional, non-structural \& structural components during 2015-2016. Iran Occup Health 2018; 15(1): 76-85. [In Persian].

21. Mirzaei F, Kakaei H, Farasati F, Zamani N. Investigation on the safety status and preparedness of Ilam's hospitals against disasters in 2012. J Ilam Univ Med Sci 2015; 22(7): 14-23. [In Persian]. 